\title{
Insulator Analysis Using Combined FIB-SEM instrument with TOF-SIMS
}

\author{
Libor Sedláček $^{1}$, Jolana Kološová ${ }^{1}$, Jaroslav Jiruše ${ }^{1}$, Fred A. Stevie ${ }^{2}$ \\ 1. TESCAN Brno, s.r.o., Libušina třída 1, 63500 Brno, Czech Republic \\ 2. North Carolina State University, 2410 Campus Shore Drive, Raleigh, NC 27695, USA
}

The development of a Time of Flight Secondary Ion Mass Spectrometer (TOF-SIMS) that can be attached to a FIB-SEM instrument provides an analyzer that very well complements the standard EDS detector [1]. However, contrary to EDS, it gives much better depth resolution, possibility of depth profiling as well as distinguishing isotopes. Insulators form a broad class of materials, but the ability to perform elemental analyses using SIMS is complicated by the tendency of the sample to charge when the ion beam is applied, therefore a charge neutralization is needed. It is usually obtained with the use of an additional electron source [2]. In our case the SEM focused e-beam has been applied for successful charge compensation as well as for imaging and navigation.

Attachment of a plasma source on a FIB-SEM provides the opportunity for many new applications because of a large volume sputtering capability $[3,4]$. For example, the use of Xe as source gas makes it possible to sputter a crater in $\mathrm{Si}$ of $100 \mu \mathrm{m} \times 100 \mu \mathrm{m} \times 100 \mu \mathrm{m}$ in 20 minutes, contrary to 18 hours for the case of $\mathrm{Ga}$ ion beam. Thus it is now possible to analyze depth profiles of $100 \mu \mathrm{m}$ thick coatings in a reasonable time. Quantitative analysis has been demonstrated for Xe plasma source and alkali elements such as Li, Na, K [5]. Detection limits below 2 ppma have been achieved for these species.

Here we present depth profiles and mass spectra from feldspar mineral bulk insulator. The sample is composed of two phases, albite and orthoclase, that are easily distinguished with an integrated TESCAN Rainbow cathodoluminescence (CL) detector, see Fig. 1a. The TOF-SIMS analysis has been carried out on both phases with mass spectra shown in Fig. 2a. Depth profiles of major elements in albite are shown in Fig. 2b. Constant level of all signals indicates satisfactory charge compensation. This is also confirmed by sharp crater edges in Fig $1 \mathrm{~b}$.

TESCAN's combined FIB-SEM instrument with integrated TOF-SIMS analyzer and CL detector has proved to be a versatile tool for in-situ high resolution SIMS analysis of non-conductive samples [6].

\section{References:}

[1] J. A. Whitby, F. Ostlund, P. Horvath, M. Gabureac, J. L. Riesterer, I. Utke, M. Hohl, L. Sedlacek, J. Jiruse, V. Friedli, M. Bechelany, J. Michler, Advances in Materials Science and Engineering 2012 (2012), article ID 180437.

[2] F.A. Stevie in "Introduction to Focused Ion Beams: Theory, Instrumentation, Applications, and Practice", ed. L.A. Giannuzzi and F.A. Stevie, (Springer, NY 2005).

[3] J. Jiruse, T. Hrncir, F. Lopour, M. Zadrazil, A. Delobe and O. Salord, Microscopy and Microanalysis 18 (Suppl. 2) (2012), pp. 652-653, doi:10.1017/S1431927612005119.

[4] T. Hrncir, F. Lopour, M. Zadrazil, A. Delobbe, O. Salord, P. Sudraud, ISTFA 2012: Conference Proceedings from the 38th International Symposium for Testing and Failure Analysis, November 11-15, 2012, Phoenix, Arizona, USA (2012), pp.26-29. 
[5] F. A. Stevie, L. Sedlacek, P. Babor, J. Jiruse, E. Principe, K. Klosova, Surf. Int. Anal. (in press). [6] The research leading to these results has received funding from the European Union Seventh Framework Program [FP7/2007-2013] under grant agreement n²80566, project UnivSEM.
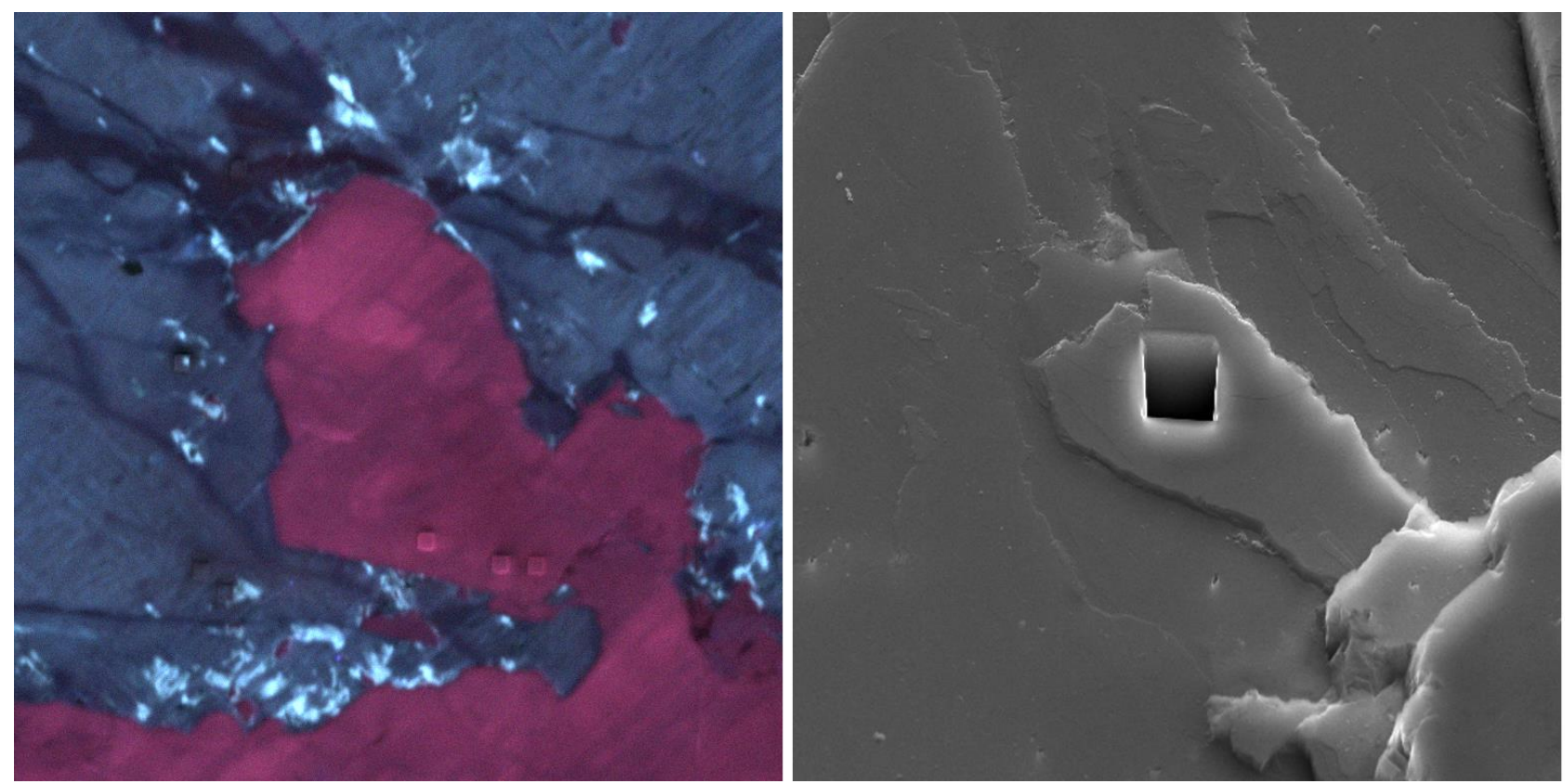

Figure 1. (a) Image of feldspar sample taken by Rainbow cathodoluminescence detector. Albite phase is violet and orthoclase is blue, field of view is $570 \mu \mathrm{m}$. (b) SEM image of orthoclase phase after TOF-SIMS analysis, field of view is $100 \mu \mathrm{m}$.
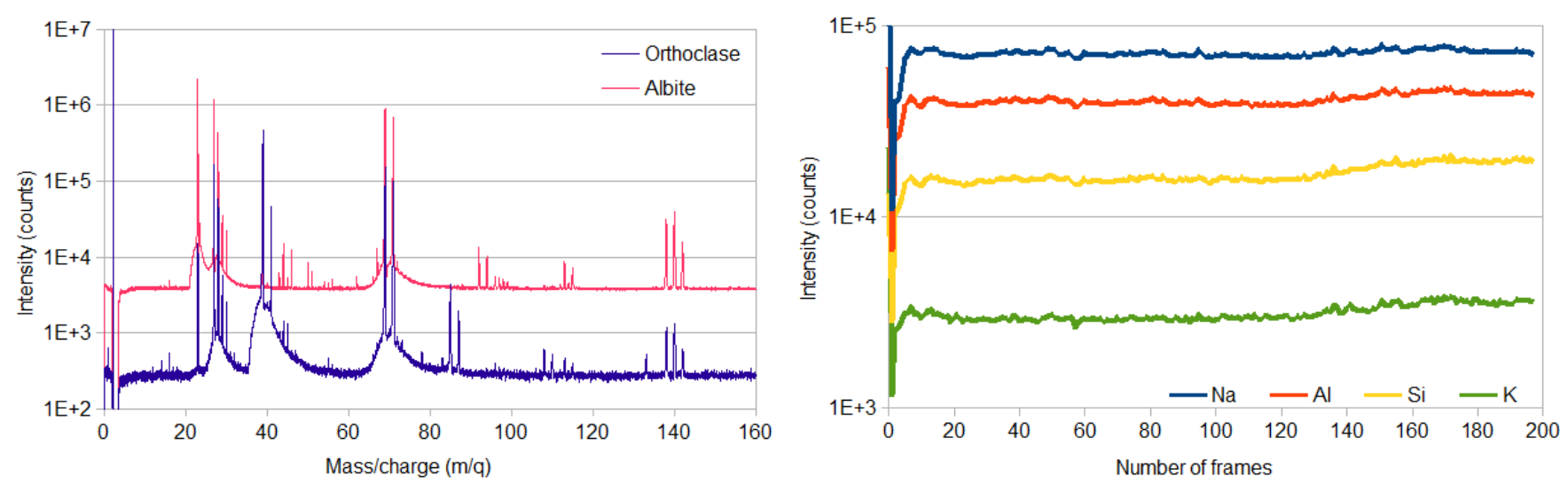

Figure 2. (a) TOF-SIMS mass spectra from two different phases of feldspar mineral. (b) Depth profiles of major elements from albite phase. Ga ion primary current was $4 \mathrm{nA}$ at $30 \mathrm{kV}$ and SEM beam current for charge compensation was $12 \mathrm{nA}$ at $30 \mathrm{kV}$. 